$\stackrel{N / N}{=}$

Global burnals Inc.

है 5 है

\title{
Mystical Experience with Cancer Patients: Insights from Psychedelic-Assisted Psychotherapy and Guided Imagery
}

\author{
By Jerry B. Brown \& Julie M. Brown
}

Florida International University

Abstract- Background: In controlled, clinical studies of the impact of psilocybin on patients with life-threatening cancers, Johns Hopkins and NYU researchers found that the "intensity of the mystical experience" induced by psychedelic-assisted psychotherapy was directly correlated with the alleviation of cancer-related mental distress.

Objective: The purpose of this article is to explore the proposition that the combination of psychotherapeutic guided imagery and psychedelic-assisted psychotherapy could not only alleviate cancer-related psychological distress but also reduce or eliminate physiological tumors. Methods: The literature surrounding "mystical experience" is discussed; the modalities of psychedelic-assisted psychotherapy and guided imagery psychotherapy with cancer patients are compared; and the anecdotal outcomes of cancer remission among private therapy guided imagery patients are presented.

Keywords: cancer, mystical experience, neuroimaging, psilocybin, psychedelic-assisted psychotherapy.

GJMR-A Classification: NLMC Code: WM 420.5.P7

Strictly as per the compliance and regulations of:

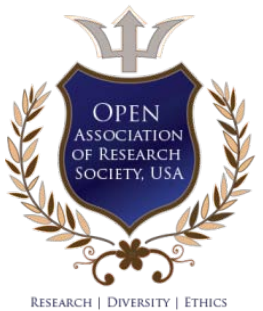

(C) 2021. Jerry B. Brown \& Julie M. Brown. This is a research/review paper, distributed under the terms of the Creative Commons Attribution-Noncommercial 3.0 Unported License http://creativecommons.org/licenses/by-nc/3.0/), permitting all non-commercial use, distribution, and reproduction in any medium, provided the original work is properly cited. 


\title{
Mystical Experience with Cancer Patients: Insights from Psychedelic-Assisted Psychotherapy and Guided Imagery
}

\author{
Jerry B. Brown ${ }^{\alpha}$ \& Julie M. Brown ${ }^{\sigma}$
}

\begin{abstract}
Background: In controlled, clinical studies of the impact of psilocybin on patients with life-threatening cancers, Johns Hopkins and NYU researchers found that the "intensity of the mystical experience" induced by psychedelic-assisted psychotherapy was directly correlated with the alleviation of cancer-related mental distress.

Objective: The purpose of this article is to explore the proposition that the combination of psychotherapeutic guided imagery and psychedelic-assisted psychotherapy could not only alleviate cancer-related psychological distress but also reduce or eliminate physiological tumors.

Methods: The literature surrounding "mystical experience" is discussed; the modalities of psychedelic-assisted psychotherapy and guided imagery psychotherapy with cancer patients are compared; and the anecdotal outcomes of cancer remission among private therapy guided imagery patients are presented.
\end{abstract}

Result: The following question is proposed for future research: can psychedelic-assisted psychotherapy augmented by guided imagery facilitate the reduction or elimination of tumors in cancer patients?

Keywords: cancer, mystical experience, neuroimaging, psilocybin, psychedelic-assisted psychotherapy.

"In both trials, the intensity of the mystical experience described by patients correlated to the degree to which their depression and anxiety decreased."

-Johns Hopkins and NYU psilocybin-cancer studies

\section{INTRODUCTION}

( ur contemporary understanding of the common elements in mystical experience is largely based on the ideas of William James (1902), The Varieties of Religious Experience, and Walter T. Stace (1961), Mysticism and Philosophy. These elements were refined, validated, and incorporated into a 30-question operational definition of mysticism, the Mystical Experience Questionnaire (MEQ30) utilized in the Johns Hopkins studies on the impact of psilocybin on reducing anxiety and depression in patients with life-threatening cancers (Barrett et al. 2015, MacLean et al. 2012).

Author a: Ph.D., is Founding Professor of Anthropology, Global \& Sociocultural Studies, Florida International University, Miami, Florida, USA.e-mail: jbbrown@gate.net

Author $\sigma:$ M.A., LMHC, is a retired integrative psychotherapist who specialized in working with cancer patients.
The five common elements of mystical experience are:

- Unity/Sacredness- deep sense of unity with all of existence; knowledge that "all is one"; profound sense of reverence.

- Positive Mood/Ecstasy- deeply felt sense of wellbeing; experience of peace and tranquility; irrepressible feelings of joy and amazement.

- Transcendence of Time and Space/Eternity- loss of usual sense of time and space; existing beyond past, present and future; entering a liminal, mythic dimension.

- Authoritative/True Self- authoritative truth value of the experience (noetic); encounter with all-knowing presence; understanding one's authentic self.

- Ineffable/Indescribable- difficulty describing the experience in words; impossibility of adequately communicating it to others.

\section{Psychedelic-assisted Psychotherapy}

Since 2006 the Johns Hopkins School of Medicine (Johns Hopkins) has been conducting the first research since the 1970s involving the administering of psilocybin to human subjects, including studies of personality changes and of psychedelic therapy for treating tobacco/nicotine addiction and cancer-related distress.

In 2016 Johns Hopkins undertook the largest ever study of psilocybin in treating chronic depression and anxiety among patients with life-threatening cancers. In this randomized, double-blind, cross-over trial, 51 patients were given a low placebo-like dose (1-3 $\mathrm{mg} / 70 \mathrm{~kg}$ of body weight) vs. a high dose (22 or 30 $\mathrm{mg} / 70 \mathrm{~kg}$ of body weight) in two sessions with six-month follow up. (Griffiths et al. 2016).

In a Journal of Psychopharmacology article, Roland R. Griffiths, Matthew W. Johnson, and colleagues report that "High-dose psilocybin produced large decreases in clinician- and self-rated measures of depressed mood and anxiety, along with increases in quality of life, life meaning, and optimism, and decreases in death anxiety" (Griffiths et al. 2016, p. 1). A six-month follow up study showed that these results were sustained in most of the participants.

Some 70 percent of the cancer patients rated the high-dose psilocybin sessions as among the top five 
"most meaningful" and "spiritually significant" life experiences. In addition, their post-session mystical experience scores served as statistically significant predictors of therapeutic efficiency in reducing anxiety and depression.

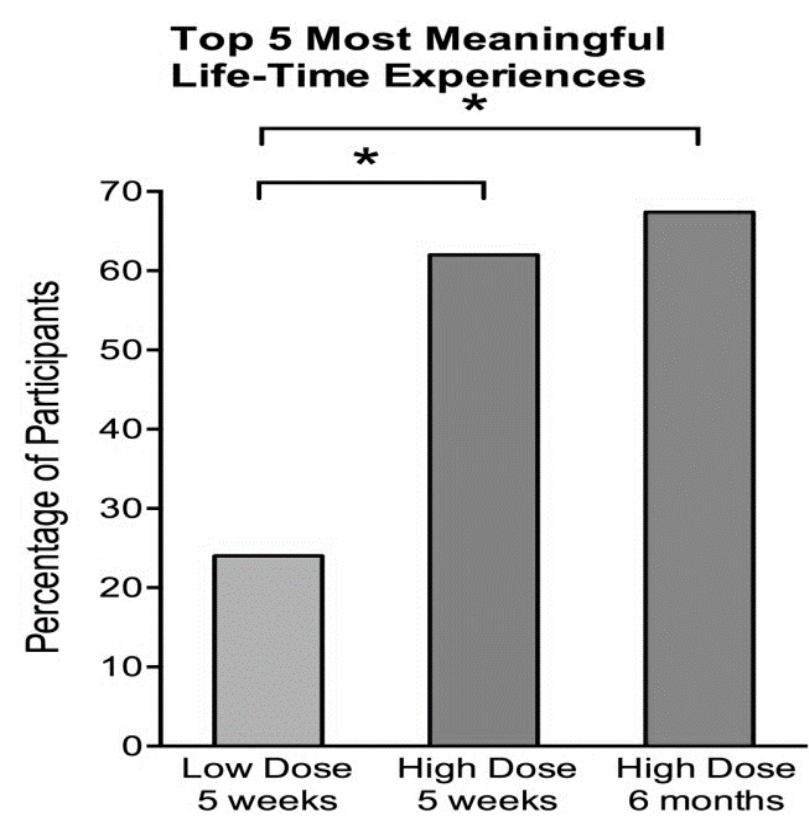

Timepoint

Source: Matthew W. Johnson, Johns Hopkins School of Medicine, "Psilocybin in the treatment of cancer-associated depression and anxiety," Power point presentation, Ottawa, 2018, slide 13.

The daughter of one study participant noted that "This opportunity allowed my dad to have vigor in his last couple of weeks of life-vigor that one would think a dying man could not possibly demonstrate. His experience gave my father peace. His peace gives me strength" (Johnson 2018, slide 16). These outcomes prompted Griffiths to observe that "It's very common for people who have profound mystical-type experiences to report very positive changes in attitudes about themselves, their lives, and their relationships with others." And to exclaim, "To see people who are so beaten down by this illness, and they start actually providing reassurance to the people who love them most, telling them 'it is all okay and there is no need to worry' - when a dying person can provide that type of clarity for their caretakers, even we researchers are left with a sense of wonder" (Schiffman 2016).

\section{a) Guided Imagery-Assisted Psychotherapy}

Julie M. Brown, coauthor of this article, is a retired psychotherapist who for twenty-five years specialized in helping cancer patients heal. In her private practice, she worked with a variety of therapeutic modalities, including guided imagery which she studied as a graduate student under her mentor in psycho synthesis.

Guided imagery, also known as visualization, is a technique through which psychotherapists help patients evoke and focus on mental images to facilitate relaxation, healing, and resolution of life issues. In guided imagery-assisted psychotherapy, a person calls on mental images to improve both emotional and physical health (see Samuels, 2003; Epstein, 1989).

This highlights an important distinction between psychedelic-assisted psychotherapy and guided imagery. The Johns Hopkins protocol is non-directive, simply encouraging study participants to "trust, let go and be open" and not providing instructions on where to focus. In contrast, the guided imagery modality is directive, with the therapist purposefully focusing patients to induce images and assisting in processing and integrating these images.

Often Brown's cancer patients turned to psychotherapy after conventional treatment (chemotherapy, radiation, pharmaceuticals) failed to reduce or eliminate tumors. In the guided imagery sessions, Brown found that patients would at times enter states of mystical experience that empowered both emotional (anxiety, depression) and physical (cancer) self-healing.

\section{b) Guided Imagery Therapy Outcomes}

Between 1986 and 2011, Brown worked with 50 cancer patients, the majority of whom achieved full remission as evaluated by oncologists. The profiles and outcomes for three patients are summarized in this table. 
Client Profiles and Guided Imagery Therapy Outcomes

\begin{tabular}{|c|c|c|c|}
\hline & Client \#1 & Client \#2 & Client \#3 \\
\hline Gender & Male & Male & Female \\
\hline Profession & Hospital CEO & Physician & Graduate Student \\
\hline Diagnosis & $4^{\text {th }}$ Stage & $4^{\text {th }}$ Stage & $3^{\text {rd }}$ Stage \\
& Prostate Cancer & Prostate Cancer & Breast Cancer \\
\hline Psychotherapy & 1 Year w/out & 2 Years w/out & $1 \frac{11 / 2 \text { Years w/out }}{\text { Treatment }}$ \\
Length & Conventional & Conventional & Conventional \\
Cancer Treatment & Cancer Treatment & Cancer Treatment \\
\hline Guided Image & Healing Garden & Spiritual Self & Warrior Self \\
\hline Main Mystical & Unity-Oneness, & Unity-Oneness, & $>$ Time/Space, \\
Experience Elements & Positive Mood & Authentic Self & Positive Mood \\
\hline Outcomes & Anxiety Reduced, & Anxiety Reduced, & Anxiety Reduced, \\
& Full Remission & Full Remission & Full Remission \\
& $>5$ Years & $>7$ Years & $>5$ Years \\
\hline
\end{tabular}

Source: Julie M. Brown, LMHC, Select Client Profiles, 1986-2011

Depending on the client's situation, Brown frequently combined guided imagery in the context of psychotherapy with a complementary cancer approach. A complementary cancer approach may integrate a variety of tools including, but not limited to, emotional release work, breath work, nutrition, exercise, and meditation. This approach can help reduce the side effects of conventional treatment, improve client emotional and physical well-being, and enhance the healing process.

Unlike the controlled Johns Hopkins study involving 51 participants, Brown's 50 case studies were neither validated by independent observers nor subjected to methodological controls-except for the patients' cancer status which was monitored by their oncologists. Nevertheless, the seminal role of mystical experience in both psychedelic-assisted psychotherapy and guided imagery psychotherapy raises important questions.

c) Guided Imagery Questions for Future Research

In the case of Brown's guided imagery outcomes with cancer patients, significant questions are:

- Can success in healing cancer utilizing guided imagery be replicated and validated? Beyond Brown's anecdotal cancer outcomes have other therapists been able to reduce or eliminate tumors utilizing guided imagery? Could healing have taken place in this context without a complementary cancer approach, or was it the combination of this approach and guided imagery that facilitated remission?

- Can psychedelic therapy protocols be integrated into guided imagery therapy?

As a psychotherapist and a person with significant personal psychedelic experience, Brown hypothesizes that the ability to administer psilocybin to psychotherapy patients could conceivably shorten the healing process, possibly from years to months. Given that clinical trials on psilocybin for addressing major depression disorder have been granted "breakthrough therapy" designation by the U.S. Food and Drug Administration, what changes in state and federal policies, and in professional regulations, would have to take place so that psychiatrists and psychotherapists could legally integrate psychedelics into conventional treatment modalities?

d) Psychedelic Therapy Questions for Future Research

In the case of Johns Hopkins psychedelic therapy outcomes with cancer patients, significant questions are:

- Can psychedelic-assisted psychotherapy be used not only to alleviate psychological anxiety and depression in patients with life-threatening cancers, but also to facilitate physiological healing among cancer patients?

Given the pivotal role of mystical experience in both short-term psychedelic-assisted psychotherapy and long-term guided imagery psychotherapy, could psychedelic therapy combined with guided imagery possibly reduce or eliminate tumors in late-stage cancer patients?

- Will long-term, costly psychotherapy eventually be replaced by short-term, more affordable psychedelic-assisted psychotherapy?

Since short-term psychedelic therapy has achieved positive and sustained outcomes in 70 percent of the participants, based on one or two high-dose psilocybin sessions administered over several weeks, will it eventually replace, or significantly enhance, longterm psychiatric and psychotherapeutic modalities which require years of treatment and cost thousands of dollars?

\section{il. Mystical Experience and Healing}

It is well-established that mystical experiences have historically played a pivotal role in indigenous shamanism and world religions, such as the miracles 
surrounding Moses' burning bush and Jesus' baptism (Brown and Brown, 2019; Brown and Brown, 2016; Winkelman, 2019). What is less well-known and quite unexpected is the discovery that mystical experiences are the catalyst for healing in contemporary psychedelic research.

Two studies of the impact of psilocybin on cancer patients, conducted at Johns Hopkins and NYU, found that "In both trials, the intensity of the mystical experience described by patients correlated with the degree to which their depression and anxiety decreased" (Hoffman 2016).

In other words, research scientists have reliably occasioned mystical experiences - "flights of the soul" traditionally thought to be beyond the scope of empirical science-in clinical settings by administering high-dose psilocybin. Furthermore, it turns out that these experiences hold the key to positive patient outcomes in psychedelic-assisted psychotherapy. Let this enigma sink in for a moment.

\section{a) Three Seminal Studies}

In the 1960s urban legends began circulating, claiming that psychedelics could allow intrepid trippers to meet spirit guides, to travel to other dimensions, and even to know God. In fact, the new science of psychedelics was in part inspired by the initiatory mystical experiences of early psychonauts: Stanislav Grof's cosmic consciousness revelations on LSD in Prague (1993, pp. 15-16); Michael Harner's near death journey on ayahuasca in the Amazon (1990, pp. 3-5); and Timothy Leary's mind-expanding awakening on psilocybin mushrooms in Cuernavaca, Mexico (1960, pp. 11-34), to name but a few. Over time, the ability of psychedelics to generate authentic mystical experiences was confirmed by three seminal studies.

The first, the Miracle of Marsh Chapel (also called the "Good Friday Experiment") was a psychedelic research experiment carried out by Walter N. Pahnke under the auspices of Leary's Harvard Psilocybin Project. On Good Friday 1962, Pahnke randomly divided twenty volunteer Protestant divinity students into two groups assembled in a small room in the basement of Marsh Chapel on the campus of Boston University. In this controlled double-blind study, half the students received capsules containing thirty milligrams of psilocybin and the other half received a large dose of niacin (vitamin B3) as a placebo. The results were compelling. Almost all members of the group receiving psilocybin reported profound mystical experiences.

As Pahnke reports, "The persons who received psilocybin experienced to a greater extent than did the controls the phenomena described by our typology of mysticism" (Doblin 2012, p. 85). He built a follow-up survey into the research design, which found that six months after the experiment the psilocybin subjects reported persistent positive, and virtually no negative changes in their attitude and behavior.

The second study showed that the Good Friday Experiment could withstand the test of time and scrutiny by independent reviewers. A 25-year follow-up investigation conducted in 1987 by then-graduate student Rick Doblin, founder of the Multidisciplinary Association for Psychedelic Studies (MAPS), documented that "all seven psilocybin subjects participating in the long-term follow-up, but none of the controls, still considered their original experience to have had genuinely mystical elements and to have made a valuable contribution to their personal lives." Doblin (2012, p. 87) concluded that Pahnke's research on synthetic psilocybin "cast considerable doubt on the assertion that mystical experiences catalyzed by drugs are in any way inferior to nondrug mystical experiences."

In assessing Pahnke's research, Walter $\mathrm{H}$. Clark, recipient of the American Psychological Association's Award for contributions to the psychology of religion, states "There are no experiments known to me in the history of the scientific study of religion better designed or clearer in their conclusion than this one" (Doblin 2012, pp. 87-88).

A third round of studies, initiated more than 40 years after the Good Friday Experiment, was conducted at Johns Hopkins School of Medicine. In two papers, Griffiths and his colleagues empirically demonstrated that psilocybin could regularly result in mystical experiences with lasting benefits for participants (Griffiths et al. 2008; Griffiths et al. 2006). These doubleblind studies found that: psilocybin was safe in structured, clinical settings; generated one of the five most meaningful life experiences for most participants; and produced improvements in mood and quality of life that were still present 14 months after the sessions.

\section{b) How Does Mystical Experience Facilitate Healing?}

The rigorous psychedelic therapy studies of stress reduction and the anecdotal guided imagery therapy cases of cancer remission described above suggest that mystical experience can facilitate both mental and physical healing. "How" this healing takes place is the theoretical Holy Grail of psychedelicassisted psychotherapy.

Our quest to unravel this mystery begins with the insights of three mind explorers: Roland R. Griffiths, grandfather of the psychedelic renaissance; Robin Carhart-Harris, pioneer of psychedelic brain neuroimaging; and Carl G. Jung, who with Sigmund Freud laid the foundations of modern psychotherapy.

In essence, Griffiths observes that "the psilocybin experience enables a sense of deeper meaning, and an understanding that in the largest frame everything is fine and that there is nothing to be fearful of" (Schiffman 2016). How the brain expands from 
ordinary consciousness to encompass this "largest frame" is visually revealed in Carhart-Harris's functional magnetic resonance imaging (fMRI) of the brain's neural pathways before and after ingesting psilocybin mushrooms.

\section{Brain's NeURAL PATHWAYS}

Before and after Magic Mushrooms
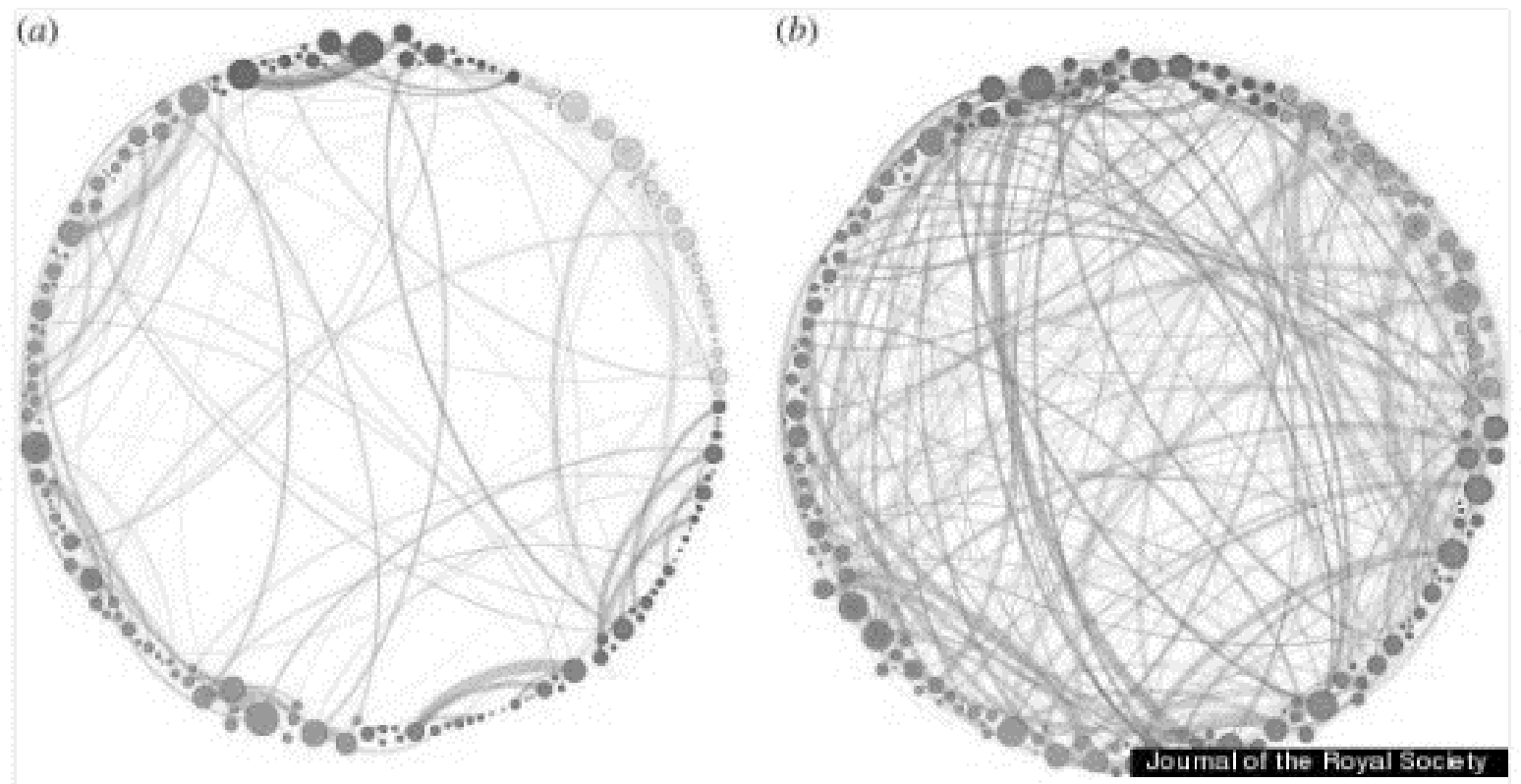

Hyperconnectivity of brain's neural pathways before and after using magic mushrooms

Journal of the Royal Society

Source: G. Petri, P. Expert, et al., Homological scaffolds of brain functional networks, Journal of the Royal Society,

December 2014, p. 8.

Psychedelics allow us to leave the brain's "default-mode network" (Carhart-Harris et al. 2014), the brain's everyday information highway, and travel into areas of the mind accessible in non-ordinary states of consciousness, thereby creating a "superhighway to the unconscious" and access to mystical experience. In summarizing the findings of neuroimaging research with psychedelic drugs, Carhart-Harris (2014, p. 18) concludes, "Indeed, psychedelics greatest value may be as a remedy for ignorance of the unconscious mind."

\section{Inner Self-healing Intelligence}

It is Jung's (2017) "spiritual self" that embodies insights that emerge from the unconscious mind. Beyond Freud's model, Jung proposes the existence of a "spiritual self," also called "spiritual consciousness." Through dreams, messages from the spiritual self are brought into awareness.

Mystical experiences arise when the doors of perception are flung wide open so that the spiritual self can surface from the depths of the psyche, empowering us to heal and understand that in the cosmic scheme of things "all is well." As one of the pioneers of psychedelic psychotherapy, Stanislav Grof has guided over 3,000 LSD sessions. Based on his unparalleled experience with LSD and encyclopedic knowledge of the psychedelic literature, Grof (2019) observes that "Entering these [holotropic, transpersonal, mystical] states activates an inner self-healing intelligence, which automatically guides the process to unconscious material that has a strong emotional charge and is close to the threshold of consciousness. It then spontaneously brings this material to the surface for processing."

In this context, it is worth noting that Grof has documented significant instances of auto-punitive emotions correlated with the emergence of cancer. In The Human Encounter with Death, he reported on research in which high dose LSD (200 to 600 micrograms) was given to terminally ill cancer patients (Grof and Halifax, 1977). In this study, Grof and associates at the Spring Grove State Hospital in Baltimore "...saw surprisingly frequent instances of severe guilt, feelings of self hatred, and autopunitive tendencies that had preceded the clinical manifestation of cancer by years or decades." They also found that "It was not infrequent that cancer patients in their LSD 
sessions saw direct links between such tendencies within themselves and their malignancies."

\section{a) Can Positive Emotions Impact Immune Response?}

To investigate the above findings from a medical perspective, it is essential to seek empirical evidence on the impact of mental states on healing cancer. It is important to go beyond the psychological phenomena of "mystical experience" and "inner selfhealing intelligence" to determine if there is physiological evidence that positive emotions, such as those engendered by mystical experience, can significantly activate the body's immune system.

Research conducted at the Faculty of Medicine at the Technion in Israel suggests that the prima facie answer to this question is "yes." Studies of mouse models involving melanoma and lung cancer found that activation of the brain's reward system helps regulate immune system function and enhances immune response (Ben-Shaanan, et. al. 2018). Specifically, activation of the dopamine-releasing neurons in the ventral tegmental area (VTA) of the brain significantly impacted tumors, resulting in a 46.5 percent reduction of tumor size after 14 days.

\section{Conclusions}

This paper shows that, in addition to appearing in dreams, the spiritual self may emerge through mystical experiences occasioned by psychedelicassisted psychotherapy or evoked by guided imagery therapy. While controlled, clinical studies $(n=51)$ at Johns Hopkins School of Medicine found that psychedelic-assisted psychotherapy alleviates anxiety, depression, and fear of death among patients with lifethreatening cancers, anecdotal observations $(n=50)$ among cancer patients being treated in private practice found that guided imagery psychotherapy reduces or eliminates tumors among advanced stage cancer patients. Based on these observations, the following question is proposed for future research: can psychedelic-assisted psychotherapy augmented by guided imagery facilitate the reduction or elimination of tumors in cancer patients?

Hopefully, these reflections on the role of mystical experience in psychotherapy will inspire further exploration of this unique phenomena that holds a key to healing and well-being.

\section{Acknowledgements}

The coauthors received no assistance in the preparation of this article and are solely responsible for its contents. The coauthors gratefully acknowledge Matthew Wayne Johnson, Ph.D., Professor of Psychiatry and Behavioral Sciences, Johns Hopkins School of Medicine, for permission to use information and slides from his power point presentations on psilocybin studies conducted at Johns Hopkins.

Conflict of interest

The coauthors have no conflicts of interest neither in writing this article nor regarding the subject matter of this article.

\section{References Références Referencias}

1. Barrett, F.S., Johnson, M.W. \& Griffiths, R.R. 2015. Validation of the revised Mystical Experience Questionnaire in experimental sessions with psilocybin, Journal of Psychopharmacology, 29(11): 1182-1190.

2. Ben-Shaana, T., Schiller, M., et. al. Modulation of anti-tumor immunity by the brain's reward system, Nature Communications, 9, July 13, 2018.

3. Brown, J., Brown, J. 2019. Entheogens in Christian art: Wasson, Allegro and the psychedelic gospels, Special Issue, Journal of Psychedelic Studies, vol. 3, issue 2.

4. Brown, J., Brown, J. 2016. The psychedelic gospels: The secret history of hallucinogens in Christianity. Park Street Press, Rochester.

5. Carhart-Harris, R.L., Leech, R., Hellyer, P.J., Shanahan, M., Feilding, A., Tagliazucchi E., Chialvo, D.R. \& Nutt. D. 2014. The entropic brain: a theory of conscious states informed by neuroimaging research with psychedelic drugs, Frontiers in Human Neuroscience, 8: 1-22.

6. Doblin, R. 2012. Pahnke's Good Friday Experiment: A long-term, follow-up and methodological critique. In: Roberts, T.B. (Ed.). Spiritual growth with entheogens: Psychoactive sacramentals and human transformation, Park Street Press, Rochester, pp. 84-93.

7. Epstein, G. 1989. Healing visualizations: Creating health through imagery, Random House, New York.

8. Griffiths, R.R., Johnson, M.W., Carducci, M.A., Umbricht, A., Richards, W.A., Richards, B.D., Cosimano, M.P. \& Kleindinst, M.A. 2016. Psilocybin produces substantial and sustained decreases in depression and anxiety in patients with lifethreatening cancer: A randomized double-blind trial, Journal of Psychopharmacology, 20(12): 1181-1197.

9. Griffiths, R.R., Richards, W.A., Johnson, M.W. \& McCann, U.D. 2008. Mystical-type experiences occasioned by psilocybin mediate the attribution of personal meaning and spiritual significance 14 months later, Journal of Psychopharmacology, 22(6): 621-632.

10. Griffiths, R.R., Richards, W.A., McCann, U. \& Jesse, R. 2006. Psilocybin can occasion mystical-type experiences having substantial and sustained personal meaning and spiritual significance, Journal of Psychopharmacology, 187(3): 268-282. 
11. Grof, S. 2019. The way of the psychonaut: Encyclopedia for inner journeys, Volumes I and II, Multidisciplinary Association for Psychedelic Studies (MAPS), Santa Cruz.

12. Grof. S. 2005. Foreword. In: Hoffman, A. LSD: My problem child. Multidisciplinary Association for Psychedelic Studies, Sarasota, pp. 5-22.

13. Grof, S. 1993. The holotropic mind: The three levels of human consciousness and how they shape our lives. HarperCollins, New York.

14. Grof, S., Halifax, J. 1977. The human encounter with death. E.P. Dutton, New York.

15. Harner, M.J. 1990. The way of the shaman. $10^{\text {th }}$ anniversary edition. HarperCollins, New York.

16. Hoffman, J. 2016. A dose of a hallucinogen from a "magic mushroom," and then lasting peace (New York Times, December 1).

17. James, W. 1902. The varieties of religious experience. Start Publishing LLC, Jersey City.

18. Johnson, M.W., Hendricks, P.S., Barrett, F.S. \& Griffiths, R.D.2019. Classic psychedelics: An integrative review of epidemiology, therapeutics, mystical experience and brain network function, Pharmacology \& Therapeutics, 197: 83-102.

19. Johnson, M.W. 2018. Psilocybin in the treatment of cancer-associated depression and anxiety, Power point presentation, Ottawa, slides 1-19.

20. Jung, C.G. 2017. Modern man is search of a soul. Reprint of 1933 U.S. edition. Houghton Mifflin Harcourt, New York.

21. Leary, T. 1960. High priest. Ronin Publishing, Oakland.

22. MacLean, K.A., Leoutsakos, J.M., Johnson. M.W \& Griffiths, R.R. 2012. Factor analysis of the Mystical Experience Questionnaire: a study of experiences occasioned by the hallucinogen psilocybin, Journal for the Scientific Study Religion, 51: 721-737.

23. Petri, G., Expert, P., Turkheimer, F., Carhart-Harris, R., Nutt, D., Hellyer, P.J. \& Vaccariono, F. 2014. Homological scaffolds of brain functional networks, Journal of the Royal Society, Issue 101, 11: 1-10.

24. Samuels, M. 2003. Healing with the mind's eyes: How to use guided imagery and visions to heal body, mind and spirit. Wiley, Hoboken, New Jersey.

25. Schiffman, R. 2016. Psilocybin: A journey beyond fear of death (Scientific American, Dec. 1). Stace. W.T. 1960. The teachings of the mystics. New American Library, New York.

26. Winkelman, M. 2019. Editor. Psychedelics in history and world religions, Special Issue, Journal of Psychedelic Studies, vol. 3, issue 2. 